\title{
KAJIAN IMPLEMENTASI PROGRAM PENILAIAN DAN PENYUSUTAN ARSIP: STUDI KASUS RECORDS CENTER FAKULTAS PERTANIAN UNIVERSITAS GADJAH MADA
}

\author{
Dinda Widy Pratiwi \\ Kementerian Energi dan Sumber Daya Mineral Republik Indonesia \\ dinda.widy.p@mail.ugm.ac.id \\ Rina Rakhmawati \\ Program Studi Kearsipan, Sekolah Vokasi, Universitas Gadjah Mada \\ rinaarsip@ugm.ac.id \\ Waluyo \\ Program Studi Kearsipan, Sekolah Vokasi, Universitas Gadjah Mada \\ waluyo@ugm.ac.id
}

\begin{abstract}
This paper was developed from final report that titled Evaluation of Appraisal and Disposal Records in Faculty of Agriculture Universitas Gadjah Mada. The appraisal and disposal of the records in Agriculture Faculty had not been conducted regularly because of the under qualified skills of records manager and the lack of facilities in archival activities. The research was conducted by observation-participant method, interview, and literature study. The results of the study provide suggestions that management of records in Agriculture Faculty of Universitas Gadjah Mada should had a workflow and must be and socialized to each unit to facilitate the final process in records management that was appraisal and disposal of the records. In addition, the authors suggested that the proposed addition of archivists who can strengthen the implementation of records management and supported by adequate facilities for both records and archivists.
\end{abstract}

Keywords: Implementasi, Penilaian, Penyusutan, Arsip

\section{Intisari}

Makalah ini merupakan pengembangan dari laporan tugas akhir berjudul Evaluasi Terhadap Program Penilaian dan Penyusutan Arsip di Fakultas Pertanian Universitas Gadjah Mada. Program penilaian dan penyusutan arsip merupakan salah satu wujud kebijakan dalam manajemen kearsipan. Penilaian dan penyusutan arsip di Fakultas Pertanian belum dilaksanakan secara berkala karena terkendala oleh jumlah arsiparis, kemampuan arsiparis, dan minimnya fasilitas yang ada dalam pelaksanaan kegiatan kearsipan. Penelitian dilaksanakan dengan metode observasi-partisipatif, wawancara, dan studi pustaka. Hasil penelitian memberikan saran jika pengelolaan arsip di lingkungan Fakultas Pertanian Universitas Gadjah Mada harus memiliki alur yang jelas dan disosialisasikan kepada setiap unit kerja untuk memudahkan proses akhir dalam manajemen kearsipan yaitu penilaian dan penyusutan. Selain itu, penulis menyarankan agar diusulkan penambahan tenaga arsiparis yang dapat memperkuat pelaksanaan pengelolaan arsip serta ditunjang dengan fasilitas yang memadai baik untuk arsip maupun arsiparis.

Kata kunci: Implementation, Appraisal, Disposal, Records 


\section{PENDAHULUAN}

Adanya peningkatan kebutuhan informasi mengharuskan penyedia informasi untuk sumber informasi bagi masyarakat secara cepat dan tepat. Sumber informasi yang merupakan rekaman kegiatan dalam media tertentu disebut arsip. Ricks (1992, 3) berpendapat, "records is recorded information, regardless of medium of characteristic, made or received by an organization that is useful in the operation of the organization". Secara teori, arsip yang digunakan dalam kegiatan organisasi pencipta disebut dengan arsip dinamis. Berdasarkan Undang-undang Republik Indonesia Nomor 43 Tahun 2009 tentang Kearsipan disebutkan bahwa arsip dinamis adalah arsip yang digunakan secara langsung dalam kegiatan pencipta arsip dan disimpan dalam jangka waktu tertentu. Berdasarkan frekuensi penggunaanya, arsip dinamis dibagi menjadi dua, yaitu arsip dinamis aktif dan inaktif. Arsip dinamis aktif adalah arsip yang frekuensi penggunaannya tinggi dan/atau terus menerus, sedangkan arsip dinamis inaktif adalah arsip yang frekuensi penggunaanya telah menurun. Arsip statis merupakan arsip yang memiliki nilai guna sekunder.

Aktivitas organisasi yang terusmenerus akan diiringi dengan peningkatan volume arsip organisasi. peningkatan volume arsip juga dipengaruhi oleh ruang lingkup dan kompleksitas tugas fungsi organisasi. Organisasi dengan ruang lingkup besar dan kompleksitas tugas fungsi yang rumit, akan menghasilkan arsip dengan tingkat pertumbuhan yang tinggi, dan sebaliknya. Peningkatan volume arsip yang sejak awal tidak dikelola dengan baik akan menimbulkan tumpukan kertas dan pada akhirnya dibiarkan begitu saja, terutama arsip yang frekuensi penggunaannya menurun (inaktif). Berdasarkan fakta di lapangan, arsip dianggap sebagai sampah ketika memasuki fase sebagai arsip dinamis inaktif. Hal ini seharusnya menjadi perhatian khusus dalam penyelenggaraan kearsipan di suatu instansi atau perusahaan. Arsip dinamis inaktif, meski telah memiliki penurunan frekuensi penggunaan, masih memiliki potensi nilai keberlanjutan untuk memberikan informasi kepada pimpinan atau pihak yang membutuhkan informasi tersebut. Pada kondisi pemahaman yang keliru tersebut, suatu organisasi dapat mengalami permasalahan berkaitan dengan temu kembali (retrieval) dan berdampak pada kebutuhan informasi organisasi. Maka, seharusnya peningkatan volume arsip juga diiringi dengan adanya pengelolaan arsip dengan prosedur yang tepat.

Upaya yang dilakukan dalam menghindari maupun menanggulangi terjadinya penumpukan fisik arsip, sulitnya penemuan kembali informasi dan hilangnya bukti kegiatan organisasi adalah melakukan penilaian terhadap arsip. Penilaian dalam hal ini adalah menentukan nilai guna dan jangka simpan arsip (Boles, 1991, 11). Paska penilaian arsip, arsiparis dapat melakukan penyusutan arsip untuk menghindari adanya penumpukan arsip. Penyusutan dapat dilakukan melalui tiga kegiatan yaitu pemindahan arsip dari unit kerja ke unit kearsipan, pemusnahan arsip yang habis masa retensi dan tidak memiliki nilai guna serta penyerahan arsip yang memiliki nilai guna sekunder ke lembaga kearsipan.

Penilaian dan penyusutan adalah dua hal yang saling berkaitan dalam pengelolaan arsip. Penilaian merupakan dasar sebelum kegiatan penyusutan dilakukan. Kegiatan tersebut merupakan proses paling penting dan paling sulit dalam program manajemen 
rekod. Hal tersebut dikarenakan adanya proses analisis penentuan kebutuhan informasi yang terekam dalam arsip untuk masa mendatang. Setelah dilakukan penilaian dan dihasilkan Jadwal Retensi Arsip (JRA)/ Daftar Arsip Musnah, Serah, Pindah, maka akan dilakukan proses penyusutan.

Berdasarkan Undang-Undang Republik Indonesia Nomor 43 tentang Kearsipan, yang wajib melaksanakan kegiatan kearsipan tidak terbatas di instansi pemerintah/swasta/perusahaan saja, tetapi juga perguruan tinggi. Universitas Gadjah Mada merupakan salah satu perguruan tinggi tertua di Indonesia. Selain itu, Universitas Gadjah Mada pun memiliki aktivitas yang terus meningkat, baik di dalam maupun di luar negeri sebagai dampak dari reputasi Universitas Gadjah Mada sebagai perguruan tinggi negeri paling presitisius di tingkat Internasional. Aktivitas yang terus meningkat tentu berdampak pada tingginya volume arsip, khususnya arsip yang berada di level unit kerja, salah satunya Fakultas Pertanian.

Arsip yang tercipta di Fakultas Pertanian merupakan arsip yang berkaitan dengan aktivitas pendidikan dan pengajaran, pengabdian masyarakat dan penelitian bidang ilmu pertanian. Penyelenggaraan kegiatan di Fakultas Pertanian pun menggunakan dana yang dibiayai oleh universitas, sehingga bukti kegiatan dan catatan informasi serta kelengkapan dokumen sebagai media pertanggungjawaban menjadi sangat penting dan memiliki urgensitas yang tinggi. Arsip yang tercipta terdiri dari arsip aktif dan arsip inaktif. Arsip aktif berada di masing-masing satuan kerja pencipta arsip sedangkan arsip dinamis inaktif disimpan di 2 ruang penyimpanan (records center). Masing-masing ruang penyimpanan berisi boks arsip dengan ukuran $40 \mathrm{~cm}$ x $20 \mathrm{~cm}$ x $27 \mathrm{~cm}$. Volume arsip di records center dihitung dengan rumus sebagai berikut:
Jumlah Boks (JB) =

\section{Volume Arsip (VA)x 100}

Lebar Boks (LB)

726 boks =

Volume Arsip (VA) $x 100$

$20 \mathrm{~cm}$

$726 \times 20$

= Volume Arsip (VA) x

100

14529

VA

$=100 \mathrm{VA}$

$=145,29 \mathrm{ML}=146 \mathrm{ML}$

Jadi, volume arsip yang ada di records center Fakultas Pertanian yaitu $146 \mathrm{ML}$ atau sekitar $12,2 \mathrm{~m}^{3}$.

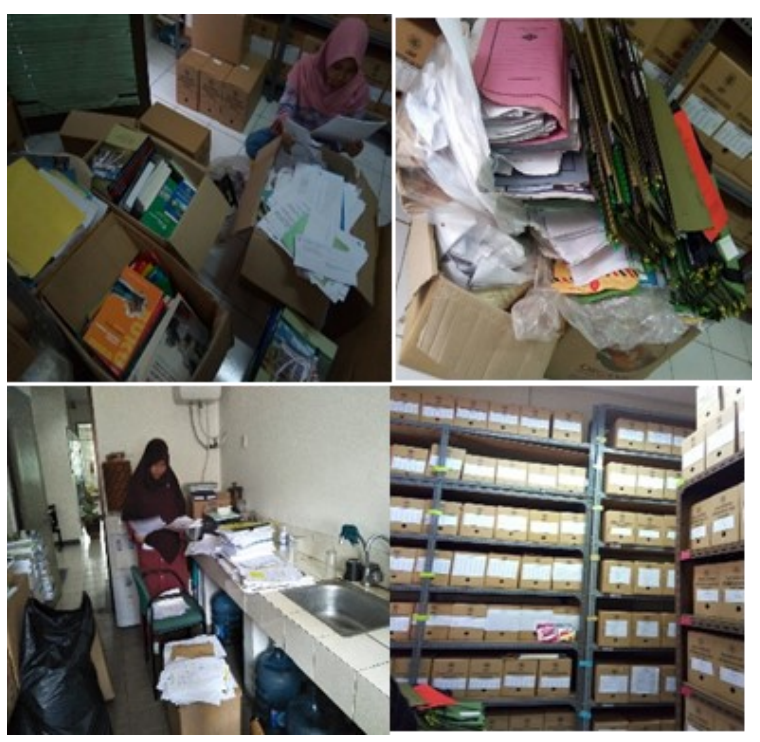

Gambar 1.

Kondisi Arsip di Fakultas Pertanian Universitas Gadjah Mada

Unit kearsipan Fakultas Pertanian UGM juga berfungsi melaksanakan program penilaian dan penyusutan arsip inaktif. Program penilaian dan penyusutan arsip inaktif merupakan salah satu kebijakan yang pada dasarnya wajib dilaksanakan oleh seluruh penyelenggara kearsipan. Dalam implementasi kebijakan tersebut tentu mengalami dinamika yang cukup kompleks. Oleh sebab itu, dlam makalah 
ini penulis akan mendeskripsikan dinamika implementasi program penilaian dan penyusutan arsip inaktif di Fakultas Pertanian Universitas Gadjah Mada.

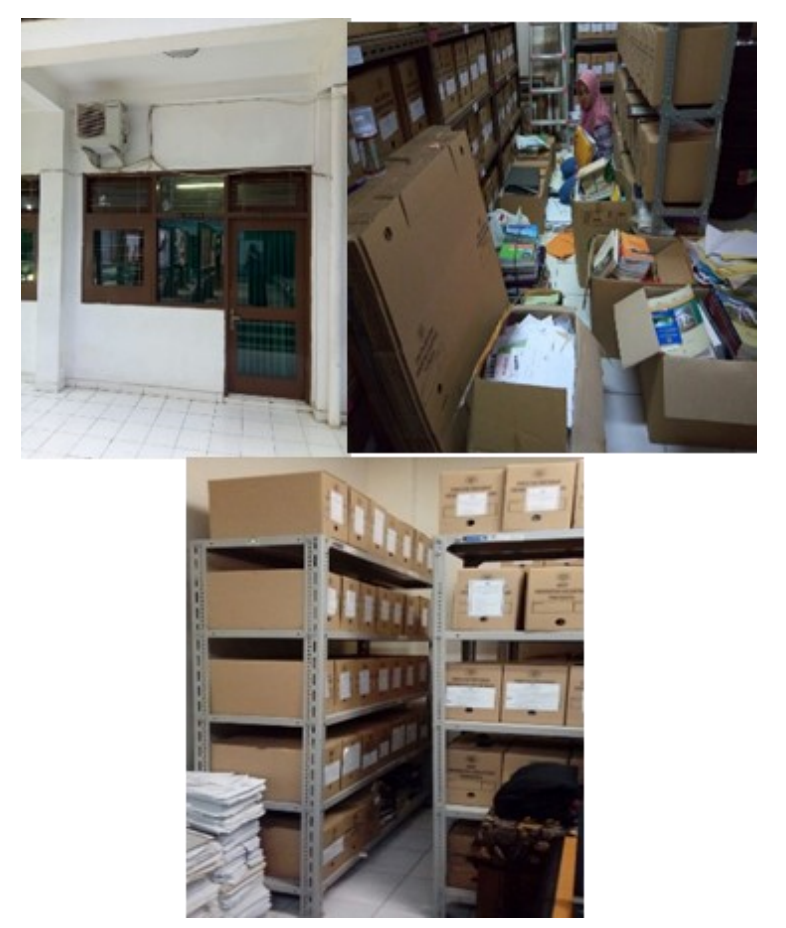

Gambar 2.

Records Center Fakultas Pertanian Universitas Gadjah Mada

Berdasarkan latar belakang tersebut, penulis merumuskan pertanyaan penelitian, yaitu bagaimana implementasi program penilaian dan penyusutan arsip yang dilakukan Records Center Fakultas Pertanian Universitas Gadjah Mada?

Pada dasarnya, kajian mengenai penilaian dan penyusutan arsip tidak banyak dilakukan oleh peneliti. Hal tersebut disebabkan rendahnya kesadaran dari organisasi, baik pemerintah maupun swasta, di Indonesia untuk melakukan kegiatan penilaian dan penyusutan. Selain itu, faktor kompleksitas proses penilaian yang dominan menekankan pada aspek analisis dalam jangka waktu yang lama berakibat pada rendahnya kemauan para stakeholders untuk melaksanakan penilaian arsip. Oleh sebab itu, makalah ini bertujuan untuk memahami implementasi program penilaian dan penyusutan arsip, serta mengetahui halhal yang harus diperbaiki atau dikembangkan dari kedua kegiatan tersebut.

Secara sederhana, istilah implementasi dimaknai sebagai proses penerapan suatu kebijakan. Berbicara mengenai kebijakan, khususnya di Indonesia, tidak banyak ditemukan keberhasilan dalam implementasinya. Menurut Hogwood dan Gunn (dalam Purwanto dan Sulistyastuti, 2012, 14-16) terdapat beberapa hal yang mendasari tidak terwujudnya perfect implementation, yaitu:

1. Hambatan eksternal organisasi, misalnya bencana alam, krisis ekonomi, dan sebagainya;

2. Waktu dan sumberdaya tidak tersedia secara memadai;

3. Kebijakan tidak didasarkan pada landasan teoritis yang kuat tentang hubungan sebab-akibat antara kebijakan dan hasil yang ingin dicapai;

4. Adanya time lag sehingga implementasi kebijakan tidak akan secara cepat dapat diketahui keberhasilannya;

5. Ketergantungan antar lembaga pelaksana

6. Implementasi jarang dilakukan oleh aktor tunggal;

7. Jarang terjadi kondisi perpaduan antara komunikasi dan koordinasi yang sempurna.

Adapun proses implementasi kebijakan secara umum dapat digambarkan sebagai berikut (Purwanto dan Sulistyastuti, 2012, 72):

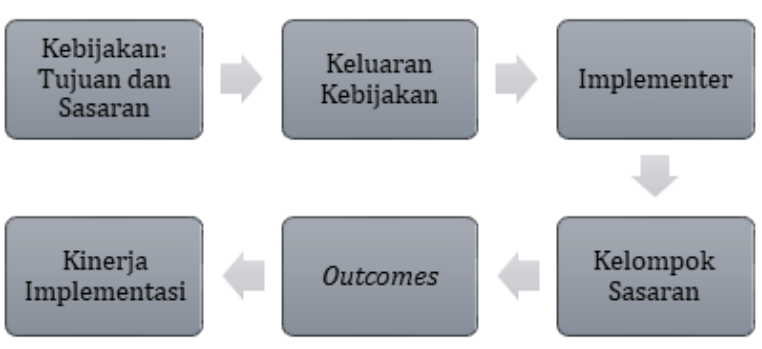




\section{METODE PENELITIAN}

Penelitian ini menggunakan pendekatan kualitatif deskriptif. Dalam proses pengumpulan data digunakan tiga metode, yaitu Observasi-Partisipatif, Wawancara, dan Studi Pustaka. Data primer diperoleh dari catatan lapangan selama observasi berlangsung dan hasil wawancara dengan narasumber. Dalam pelaksanaan observasi-partisipatif, penulis ikut berpartisipasi dalam kegiatan kearsipan yang dilaksanakan oleh records center / unit kearsipan Fakultas Pertanian Universitas Gadjah Mada. Metode wawancara dilakukan dengan bertanya pada orang yang bertugas dalam bidang Kearsipan dan orang yang berpengaruh di instansi tersebut. Hal tersebut dilakukan karena untuk menggali informasi yang dibutuhkan, penulis mencari narasumber yang berkaitan langsung dengan tema tugas akhir yang telah ditentutkan. Penulis melakukan wawancara secara formal maupun informal. Wawancara dilaksanakan oleh penulis dengan mendalam dan pengajuan pertanyaan dilaksanakan secara terstruktur. Melalui proses wawancara ini, penulis membuat daftar pertanyaan yang berkaitan dengan tema Penilaian dan Penyusutan arsip dan diajukan kepada Kepala Kantor Administrasi dan Arsiparis Fakultas Pertanian. Untuk melengkapi data penelitian, penulis menggunakan metode studi pustaka, yaitu dengan memilih dan mencari buku yang sesuai. Sumber yang akan digunakan oleh penulis yaitu buku, jurnal, maupun sumber lainnya yang berkaitan dengan Penilain dan Penyusutan Arsip.

\section{HASIL DAN PEMBAHASAN}

\section{Implementasi Penilaian Arsip di Records Center Fakultas Pertanian Universitas Gadjah Mada}

Penilaian arsip merupakan bagian dari komponen penyusutan arsip dan tidak dapat dipisahkan dari keseluruhan program records management (Utomo,
1995, 5). Penilaian merupakan salah satu proses paling berat dalam pengelolaan arsip karena membutuhkan kerja intelektual untuk menentukan keputusan nasib akhir arsip didasarkan pada referensi kebijakan organisasi pencipta (Boles, 1991, 5). Penilaian terhadap arsip tidak dapat dilakukan sendiri oleh arsiparis, melainkan harus berkoordinasi dengan unit pencipta arsip, pimpinan instansi dan elemen lain yang berkaitan dengan keberadaan arsip tersebut. Penilaian memerlukan konsep yang matang terutama pemahaman terhadap organisasi pencipta arsipnya. Maher (1992, 46-47) menyebutkan the core of appraisal work is gathering data about the characteristics of records and answering question about their potential administrative, fiscal, legal, research, and archival use. Lekoko Kenoshi dan Trevor Moatlhodi (2012) mendefinisikan bahwa penilaian yaitu select records (with enduring value) for permanent preservation and those that are identified as ephemeral for destruction.

Arsip memiliki nilai guna primer dan nilai guna sekunder yang ikut serta menentukan proses penilaian suatu arsip. Nilai guna primer meliputi nilai guna administratif, hukum, keuangan, ilmiah dan perorang. Nilai guna sekunder meliputi nilai kebuktian dan informasional (Martono, 1994, 55-60). Pada umumnya, beberapa instansi membentuk tim penilaian untuk merumuskan jangka simpan arsip dan menentukan jadwal retensinya. PP Nomor 28 Tahun 2012 tentang Pelaksanaan Undang-Undang Republik Indonesia Nomor 43 Tahun 2009 tentang Kearsipan menyebutkan bahwa panitia penilaian arsip ditetapkan oleh pimpinan pencipta arsip. Ouput dari proses penilaian yaitu Jadwal Retensi Arsip (JRA) yang terdiri dari daftar arsip usul musnah, yang akan diserahkan ke lembaga kearsipan, menjadi dinamis inaktif, dan sebagainya. Berdasarkan 
teori-teori tersebut, dapat disimpulkan bahwa penilaian merupakan proses penyeleksian arsip untuk menentukan jangka simpannya.

Dalam pelaksanaan penilaian dan penyusutan arsip, Fakultas Pertanian menggunakan cara yang didasarkan pada nilai guna dan Jadwal Retensi Jadwal Retensi Arsip (JRA) berkaitan dengan masa simpan arsip. Sebagai bagian dari Universitas Gadjah Mada, saat ini Fakultas Pertanian UGM menggunakan Jadwal Retensi yang berasal dari Arsip Universitas sebagai alat penilaian. Jadwal Retensi Arsip Universitas Gadjah Mada dikeluarkan dalam bentuk Peraturan Rektor Universitas Gadjah Mada Nomor 408/P/ SK/HT/2009 tentang Jadwal Retensi. Arsip dan Pedoman Penyusutan Arsip di Lingkungan Universitas Gadjah Mada. Selain tabel Jadwal Retensi Arsip, Peraturan Rektor Universitas Gadjah Mada Nomor 408/P/SK/HT/2009 juga disebutkan bahwa kebijakan penggunaan Jadwal Retensi Arsip antara Arsip Universitas dengan Arsip Fakultas bersifat sentralisasi, sedangkan pelaksanaannya bersifat desentralisasi. Unsur dari Jadwal Retensi Arsip UGM yang juga digunakan oleh Fakultas Pertanian UGM terdiri dari Nomor, Jenis Arsip, Masa Aktif, Masa Inaktif dan Keterangan.

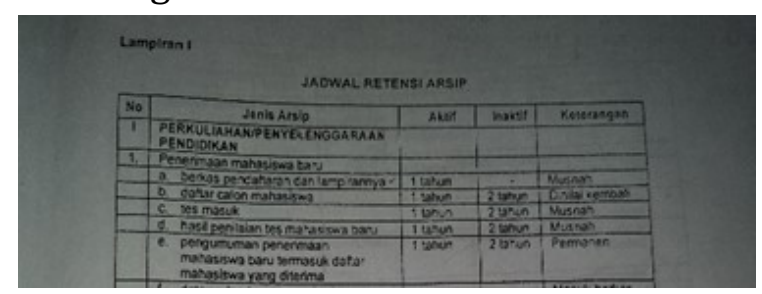

Gambar 3. Format Jadwal Retensi Arsip Fakultas Pertanian Universitas Gadjah Mada

Penjelasan dari masing-masing unsur tersebut, yaitu:

1. Nomor dalam unsur JRA terdiri dari angka romawi dan angka arab. Angka romawi menunjukkan subjek utama dan angka arab menjadi sub subjek dari arsip yang tercipta dalam ruang lingkup perguruan tinggi Universitas Gadjah Mada.

2. Jenis Arsip, berisi informasi arsip yang diturunkan dari subjek utama dan sub subjek arsip yang tercipta di Universitas Gadjah Mada sebagai lembaga pendidikan tinggi. Setiap informasi dikelompokan berdasarkan masalah.

3. Masa Aktif dan Inaktif, berkaitan dengan masa simpan arsip. Masa aktif merupakan masa simpan arsip dengan jangka waktu 1 tahun, 2 tahun hingga jangka waktu tertentu sesuai dengan kebutuan informasi unit pencipta. Misalnya, arsip keuangan berada pada masa aktif sampai dengan 1 tahun setelah audit dilakukan, arsip penelitian berlaku aktif sampai proses penelitian selesai, arsip berita acara pemindahan, pemusnahan maupun penyerahan arsip disimpan selamanya oleh instansi asal. Sedangkan masa inaktif merupakan masa simpan arsip selama 2 tahun, 3 tahun, 4 tahun, 5 tahun, dan 10 tahun.

Keterangan, merupakan nasib akhir arsip apakah akan dimusnahkan, dinilai kembali, permanen dan disimpan dalam jangka waktu 30 tahun. Apabila mengacu pada Peraturan Kepala ANRI Nomor 9 Tahun 2017 tentang Pedoman Penyusutan Arsip di Lingkungan Arsip Nasional Republik Indonesia dan Lampiran 1 Peraturan Kepala ANRI Nomor 19 Tahun 2011 tentang Pedoman Penilaian Kriteria dan Jenis Arsip yang Memiliki Nilai Guna Sekunder, halaman 2, terdapat 2 poin utama dalam proses penilaian arsip. (1) Penilaian arsip harus dirumuskan oleh tim penilai paling sedikit 3 orang yang terdiri dari unsur unit pengolah, arsiparis, dan unit kearsipan; (2) prosedur penilaian arsip bernilai guna sekunder meliputi persiapan, pendataan, penilaian, dan penyusunan daftar arsip. Selain itu, 
proses penilaian mengandung 4 unsur penting lainnya yaitu functional association, procedural association, research association, dan historical association (Penn, 1989, 167). Secara resmi, penilaian arsip di Fakultas Pertanian Universitas Gadjah Mada telah dilaksanakan sebanyak 1 kali. Berdasarkan hasil observasi dan wawancara, tidak disebutkan secara spesifik terkait waktu pelaksanaan kegiatan penilaian arsip di Fakultas Pertanian. Berdasarkan keterangan dari 2 pegawai arsiparis, hanya 1 pegawai yang menyebutkan bahwa penilaian pernah dilaksanakan sekitar tahun 2015. Penilaian arsip pada waktu tersebut dibantu oleh tenaga arsiparis dari Arsip Universitas. Proses penilaian arsip dapat dicermati pada bagan alur berikut:

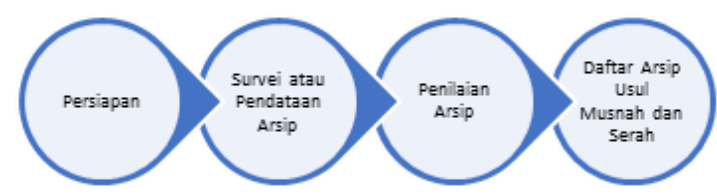

Bagan 1. Alur Penilaian Arsip di Fakultas Pertanian Universitas Gadjah Mada

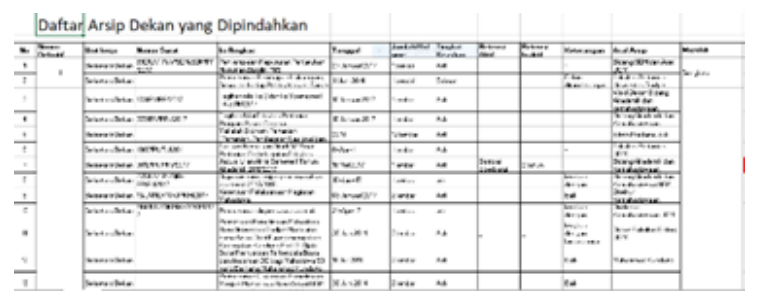

Gambar 4. Daftar Arsip Usul Pindah

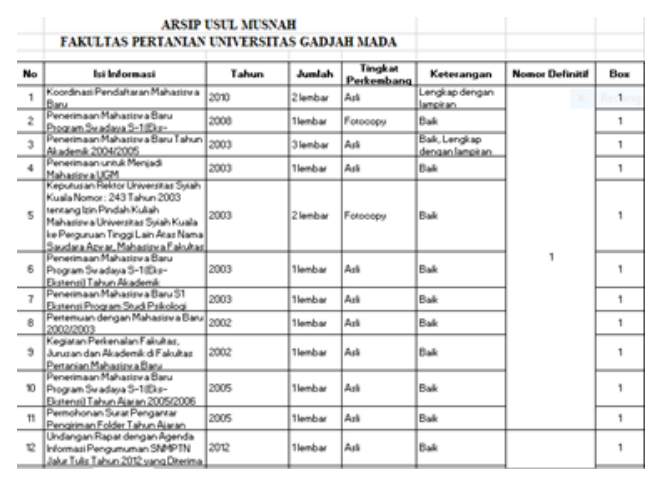

Gambar 5. Daftar Arsip Usul Musnah
Berdasarkan informasi yang didapatkan melalui wawancara dengan Sri Darwanti (arsiparis Fakultas Pertanian UGM), penilaian berpedoman pada Jadwal Retensi Arsip Universitas Gadjah Mada dan dianalisis nilai guna berdasarkan kebutuhan Fakultas Pertanian. Melihat data yang ditemukan di lapangan, terdapat sekitar 5946 arsip yang akan diserahkan dan 3065 arsip usul musnah. Arsip yang dinilai berasal dari seluruh unit kerja di Fakultas Pertanian Universitas Gadjah Mada. Sebelum penilaian dilaksanakan, beberapa unit kerja di Fakultas Pertanian telah membuat daftar arsip yang diciptakan, diterima, dan disimpan oleh unit kerja masing-masing, namun belum semua unit kerja melakukan hal yang sama. Selama proses PKL dilaksanakan, diketahui unit kerja yang telah melaksanakan proses pendataan arsip yaitu unit keuangan, unit tata usaha, akademik dan kemahasiswaan, dan kepegawaian. Sedangkan, salah satu yang belum melaksanakan kegiatan pendataan arsip adalah sekretariat dekan. Hal ini berpengaruh pada kemudahan dalam melaksanakan proses penilaian. Arsip yang sudah diinput ke dalam daftar arsip lebih memudahkan proses penilaian karena tidak perlu mendeskripsi arsip sebelum dilaksanakan penilaian masingmasing arsip. Daftar arsip usul musnah maupun arsip yang akan diserahkan seharusnya dilegalisasi terlebih dahulu oleh tim penilai, pejabat tinggi fakultas dan pimpinan masing-masing unit kerja.

\section{Implementasi Penyusutan Arsip di Records Center Fakultas Pertanian Universitas Gadjah Mada}

Penyusutan arsip adalah kegiatan pengurangan jumlah arsip dengan cara pemindahan arsip inaktif dari unit pengolah ke unit kearsipan, pemusnahan arsip yang tidak memiliki nilai guna, dan penyerahan arsip statis kepada lembaga kearsipan. Berdasarkan Undang-undang 
Nomor 43 Tahun 2009 tentang Kearsipan, penyusutan dibagi menjadi 3, yaitu :

1. Pemindahan arsip, yaitu pemindahan arsip dari central Gile (arsip aktif) ke records center (arsip inaktif), atau dari records center (arsip inaktif) ke lembaga kearsipan (arsip statis).

2. Penyerahan arsip, yaitu penyerahan arsip statis dai pusat arsip (records center) kepada lembaga kearsipan seperti lembaga kearsipan pusat (ANRI), BPAD, atau Arsip Perguruan tinggi. Peraturan tentang penyerahan arsip diatur lebih lanjut oleh Undang-Undang Nomor 43 Tahun 2009 tentang Kearsipan di Pasal 53 :

1) Lembaga negara tingkat pusat wajib menyerahkan arsip statis kepada ANRI.

2) Lembaga negara di daerah wajib menyerahkan arsip statis kepada ANRI sepanjang instansi induknya tidak menentukan lain.

3) Satuan kerja perangkat daerah dan penyelenggara pemerintahan daerah provinsi wajib menyerahkan arsip statis kepada arsip daerah provinsi.

4) Satuan kerja perangkat daerah dan penyelenggara pemerintahan daerah kabupaten/kota wajib menyerahkan arsip statis kepada arsip daerah kabupaten/kota.

5) Satuan kerja di lingkungan perguruan tinggi negeri wajib menyerahkan arsip statis kepada arsip perguruan tinggi di lingkungannya.

6) Perusahaan wajib menyerahkan arsip statis kepada lembaga kearsipan berdasarkan tingkatannya sesuai dengan ketentuan peraturan perundang -undangan.
Arsip statis sebagaimana dimaksud pada ayat (1) sampai dengan ayat (6) adalah arsip yang: memiliki nilai guna kesejarahan; dan telah habis retensinya dan berketerangan dipermanenkan sesuai dengan JRA. Selain arsip statis sebagaimana dimaksud pada ayat (7), arsip yang tidak dikenali penciptanya atau karena tidak adanya JRA dan dinyatakan dalam DPA oleh lembaga kearsipan dinyatakan sebagai arsip.

Adapun implementasi penyusutan di Fakultas Pertanian Universitas Gadjah Mada meliputi:

a. Pemindahan arsip dari unit kerja ke records center di Fakultas Pertanian UGM dilaksanakan secara mandiri oleh unit kerja yang bersangkutan. Hal ini dibuktikan dengan pernyataan yang disampaikan saat proses wawancara oleh $\mathrm{Bu}$ Sri Darwanti (arsiparis Fakultas Pertanian UGM) bahwa pemindahan hanya dilaksanakan dengan memindahkan fisiknya saja karena ruang penyimpanan di unit kerja sudah tidak memiliki kapasitas sebagai tempat penyimpanan. Saat ini, Fakultas Pertanian tidak memiliki peraturan khusus yang mengatur alur pemindahan arsip dari unit kerja ke records center. Tahapan yang dilaksanakan pada proses pemindahan arsip dapat dicermati pada bagan alur berikut:

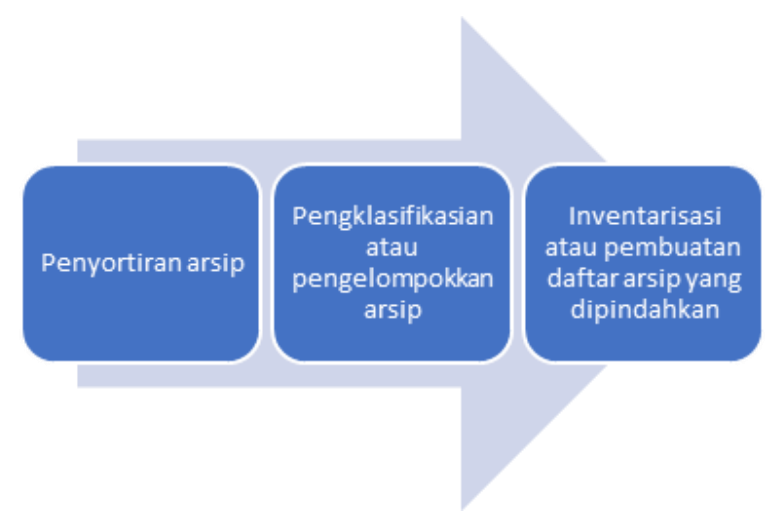

\footnotetext{
Bagan 2. Proses Pemindahan Arsip ke

Records Center Fakultas Pertanian Universitas Gadjah Mada
} 
Selama penelitian berlangsung, tidak semua unit kerja memindahkan arsip dalam kondisi yang sudah tertata. Beberapa unit kerja yang memindahkan arsip dalam kondisi yang sangat kacau, tidak ada penataan, klasifikasi, pemeliharaan, bahkan tercampur dengan sampah. Berdasarkan kasus yang ditangani, proses pemindahan yang dilakukan adalah pemindahan arsip Dekan Fakultas Pertanian. Arsip yang dipindahkan merupakan arsip-arsip dekan yang sebelumnya ditempatkan di pantry (dapur), berserakan, tidak terklasifikasi, dan bercampur dengan sampah plastik dan sampah kertas, serta tidak memiliki daftar arsip. Bahkan, beberapa arsip yang ditemukan masih dalam kondisi dinamis aktif karena tercipta pada akhir tahun 2017. Setelah fisik arsip dipindahkan ke records center dilakukan tahapan pemindahan tanpa adanya dasar landasan kerja yang digunakan.

b. Pemusnahan arsip harus didahului dengan adanya daftar pertelaan arsip, penilaian, mobilisasi pejabat dari masing-masing unit kerja untuk pelaksanaan pemusnahan arsip, dan berita acara pemusnahan. Ditinjau dari prosesnya, tahapan menuju pemusnahan yang diterapkan oleh Fakultas Pertanian dibagi menjadi dua, yaitu (a) memusnahkan arsip yang telah terdaftar sebagai arsip usul musnah, (b) memusnahkan arsip yang diprediksi sudah tidak memiliki nilai guna tanpa adanya penilaian maupun pemberitahuan kepada pejabat di Fakultas yang berhak diikutsertakan dalam perumusan pemusnahan arsip. Fakultas Pertanian Universitas Gadjah Mada, telah berencana untuk memusnahkan sebagian arsip yang telah dinilai dan menghasilkan produk yaitu daftar arsip usul musnah dan sebagian lain yang sudah tidak memiliki nilai guna. Akan tetapi, rencana tersebut belum terealisasi, dikarenakan arsiparis Fakultas Pertanian belum mampu melaksanakan pemusnahan karena kurangnya sumberdaya manusia, tidak adanya sarana penunjang, tidak adanya bimbingan berkelanjutan dari Arsip Universitas Gadjah Mada dalam pelaksanaan pemusnahan. Saat ini, Fakultas Pertanian belum menerapkan standar baku pemusnahan arsip, dan belum pernah melaksanakan pemusnahan arsip.

\section{KESIMPULAN}

Berdasarkan hasil penelitian di records center Fakultas Pertanian Universitas Gadjah Mada, dapat disimpulkan bahwa kondisi arsip di Fakultas Pertanian Universitas Gadjah Mada sudah cukup baik, namun ditemukan beberapa kegiatan dalam manajemen kearsipan yang belum memiliki kesesuaian antara praktik di lapangan dan teori kearsipan, salah satunya adalah praktik penilaian dan penyusutan. Secara penataan arsip, Fakultas Pertanian sudah melaksanakan klasifikasi arsip berdasarkan subjek informasi arsip yang tercipta, memiliki ruang penyimpanan, dan sarana pendukung.

Fakultas Pertanian menggunakan peraturan yang menginduk pada Arsip Universitas Gadjah Mada sebagai lembaga kearsipan di UGM. Dalam kegiatan penilaian dan penyusutan, Fakultas Pertanian berpedoman pada Peraturan Rektor Universitas Gadjah Mada Nomor 408/P/SK/HT/2009 tentang Jadwal Retensi Arsip dan Pedoman Penyusutan Arsip di Lingkungan Universitas Gadjah Mada ditambah dengan peraturan kearsipan lainnya yaitu Undang-undang Nomor 43 Tahun 2009 tentang 
Kearsipan.

Sampai dengan penulisan makalah ini, Fakultas Pertanian telah melaksanakan kegiatan penilaian arsip sebanyak 1 kali dan penyusutan arsip yang meliputi kegiatan pemindahan. Penilaian dan penyusutan arsip di Fakultas Pertanian belum dilaksanakan secara prosedural karena belum melibatkan pimpinan tinggi fakultas, universitas maupun pimpinan unit kerja dalam penentuan retensi dan penyusutan arsip, tidak ada verifikasi daftar arsip dari pihak yang bersangkutan dan belum adanya realisasi pemusnahan dan penyerahan. Sedangkan, untuk proses pemindahan belum sesuai dengan teori kearsipan seperti tidak adanya berita acara pemindahan dan lampiran daftar arsip yang dipindahkan. Selain itu, Fakultas Pertanian sudah memiliki SOP yang mengatur tentang penyusutan arsip di lingkungan Fakultas Pertanian, namun belum diterapkan dengan baik dan disosialisasikan.

Kendala dalam penilaian dan penyusutan yaitu sumberdaya manusia kearsipan dan fasilitas yang belum memadai dari segi kualitas dan kompetensi. Arsiparis Fakultas Pertanian sudah memasuki usia lanjut sehingga kemampuan untuk mengikuti perkembangan kearsipan menjadi terbatas. Dampak lanjutan dari faktor usia sumber daya manusia adalah tidak adanya kerja tim yang sinergis dan berkelanjutan dalam pelaksanaan implementasi penilaian dan penyusutan, khususnya di records center. Akibatnya, hal tersebut pun membatasi kecepatan dan ketepatan dalam penilaian dan penyusutan arsip.

\section{Daftar Pustaka}

Basuki, Sulistyo. Manajemen Arsip Dinamis. Jakarta: PT. Gramedia Pustaka Utama. 2003.

Boles, Frank. Archival Appraisal. New York: Neal-Schuman Publishers,
Inc, 1991.

Buku Spesial Dies Fakultas Pertanian Universitas Gadjah Mada "Enam Puluh Lima Tahun Mengabdi pada Bangsa". Fakultas Pertanian Universitas Gadjah Mada.

Brichford, Maynard J. Archives and Manuscript : Appraisal and Accessioning. Chicago: Society of American Archivist. 1977.

Maher, William J., The Management of College and University Archives. London: The Scarecrow Press, Inc. 1992.

Martono, Budi. Penyusutan dan Pengamanan Arsip Vital dalam Manajemen Kearsipan. Jakarta: Pustaka Sinar Harapan. 1997.

Muhidin, Sambas Ali, Hendri. Manajemen Kearsipani. Bandung: CV Pustaka Setia. 2016.

Musliichah. Bunga Rampai Kearsipan. Yogyakarta : Gadjah Mada University Press. 2015.

Penn, Ira A., et.al. Records Management Handbook. England: Gower Publishing Company. 1989.

Ricks, Betty R., et.al., Information and Image Management: A Records System Approach: Cincinnati: South Western Publishing Co. 1992.

Schellenberg, T.R.., The Management of Archives. New York: Columbia University Press.

Zainal Arifin. Evaluasi Pembelajaran. Jakarta: Direktorat Jenderal Pendidikan Islam. 2012

Lampiran 1 Peraturan Kepala Arsip Nasional Republik Indonesia 
Nomor 19 Tahun 2011 tentang Pedoman Penilaian Kriteria dan Jenis Arsip yang Memiliki Nilai Guna Sekunder.

Peraturan Rektor Universitas Gadjah Mada Nomor 408/P/SK/HT/2009 tentang Jadwal Retensi Arsip dan Pedoman Penyusutan Arsip di Lingkungan Universitas Gadjah Mada.

Peraturan Kepala ANRI Nomor 9 Tahun 2017 tentang Pedoman Penyusutan Arsip di Lingkungan Arsip Nasional Republik Indonesia.

Peraturan Kepala Arsip Nasional Republik Indonesia Nomor 16 Tahun 2012 tentang Pedoman Pengelolaan Arsip Kartografi dan Kearsitekturan.

Peraturan Pemerintah Nomor 28 Tahun 2009 tentang Penyelenggaraan Undang-undang Nomor 43 Tahun 2009 tentang Kearsipan.

Undang-undang Nomor 43 Tahun 2009 tentang Kearsipan.

Undang-undang Nomor 11 Tahun 2008 tentang Informasi dan Transaksi Elektronik.

Calidoni, Federica. Evaluations : Definitions, methods, and Models. Sweden: Swedish Institute for Growth Policy Studies.

Istiqoriyah, Lilik. Pengembangan Profesionalitas SDM Kearsipan Volume 2. Al-Kuttab. 2015.

Kenoshi, Lekoko, Trevor Moatlhodi. Journal The Determination of Value in Archival Science and The Ever Evolving Theories of Records Selection Volume 23 (1). The Eastern Librarian. 2012.
Taufik, Amin, et.al. Pengantar Konsep Informasi, Data, dan Pengetahuan: Jakarta: Universitas Terbuka.

Utomo, Djoko. Modul Appraisal and Disposal of Records. Hanoi: Sarbica Seminar. 1995.

\section{Informan}

\begin{tabular}{|l|l|l|l|}
\hline No & Nama & Jabatan & Umur \\
\hline 1 & Kisnadi & Arsiparis & $\begin{array}{l}54 \\
\text { Tahun }\end{array}$ \\
\hline 2 & $\begin{array}{l}\text { Sri } \\
\text { Darwanti }\end{array}$ & Arsiparis & $\begin{array}{l}53 \\
\text { Tahun }\end{array}$ \\
\hline
\end{tabular}

